\title{
Targeted next-generation sequencing of head and neck squamous cell carcinoma identifies novel genetic alterations in HPV+ and HPV- tumors
}

Matthias Lechner ${ }^{1,2+}$, Garrett M Frampton ${ }^{3 \dagger}$, Tim Fenton ${ }^{1}$, Andrew Feber ${ }^{1}$, Gary Palmer ${ }^{3}$, Amrita Jay $^{4}$, Nischalan Pillay ${ }^{1}$, Martin Forster ${ }^{1,2}$, Maureen T Cronin ${ }^{3}$, Doron Lipson ${ }^{3}$, Vincent A Miller ${ }^{3}$, Timothy A Brennan ${ }^{3}$, Stephen Henderson ${ }^{1}$, Francis Vaz², Paul O'Flynn², Nicholas Kalavrezos ${ }^{2}$, Roman Yelensky ${ }^{3}$, Stephan Beck? Philip J Stephens ${ }^{3}$ and Chris Boshoff ${ }^{*}$

\begin{abstract}
Background: Human papillomavirus positive (HPV+) head and neck squamous cell carcinoma (HNSCC) is an emerging disease, representing a distinct clinical and epidemiological entity. Understanding the genetic basis of this specific subtype of cancer could allow therapeutic targeting of affected pathways for a stratified medicine approach.

Methods: Twenty HPV+ and 20 HPV- laser-capture microdissected oropharyngeal carcinomas were used for pairedend sequencing of hybrid-captured DNA, targeting 3,230 exons in 182 genes often mutated in cancer. Copy number alteration (CNA) profiling, Sequenom MassArray sequencing and immunohistochemistry were used to further validate findings.

Results: HPV+ and HPV- oropharyngeal carcinomas cluster into two distinct subgroups. TP53 mutations are detected in 100\% of HPV negative cases and abrogation of the G1/S checkpoint by CDKN2A/B deletion and/or CCND1 amplification occurs in the majority of HPV- tumors.

Conclusion: These findings strongly support a causal role for HPV, acting via p53 and RB pathway inhibition, in the pathogenesis of a subset of oropharyngeal cancers and suggest that studies of CDK inhibitors in HPV- disease may be warranted. Mutation and copy number alteration of PI3 kinase (PI3K) pathway components appears particularly prevalent in HPV+ tumors and assessment of these alterations may aid in the interpretation of current clinical trials of PI3K, AKT, and mTOR inhibitors in HNSCC.
\end{abstract}

\section{Background}

Human papillomavirus-related (HPV+) head and neck squamous cell carcinoma (HNSCC) is a subgroup of HNSCC where the incidence is increasing in most developed countries [1]. The vast majority of HPV+ HNSCC originate from the oropharynx, and in particular the tonsillar beds [2]. These tumors are almost exclusively associated with HPV-16, have integrated and functionally

\footnotetext{
* Correspondence: c.boshoff@ucl.ac.uk

+ Contributed equally

'UCL Cancer Institute, University College London, 72 Huntley Street, London, WC1E 6BT, UK

Full list of author information is available at the end of the article
}

active E6 and E7 viral oncoproteins, and compared to HPV-negative tumors appear to have an overall better outcome, independent of treatment modality [3].

Whole-exome sequence analysis was previously performed to reveal the mutational landscape of HNSCC $[4,5]$. These studies showed that $>80 \%$ of tumors contain TP53 mutations and strikingly up to $20 \%$ have loss-offunction NOTCH1 mutations. However, in these two studies, only seven and four HPV+ samples were included, respectively. Both studies confirmed the lack of TP53 mutations compared to HPV-samples, and overall, a lower mutational burden in HPV+ disease.
C Biomed Central

C 2013 Lechner et al.; licensee BioMed Central Ltd. This is an open access article distributed under the terms of the Creative Commons Attribution License (http://creativecommons.org/licenses/by/2.0), which permits unrestricted use, distribution, and reproduction in any medium, provided the original work is properly cited. 
To further understand the contribution of somatic genomic alteration in the pathogenesis of HPV+ HNSCC we employed paired-end sequencing of hybrid-captured DNA, targeting 3,230 exons in 182 of the most common cancer-altered genes, plus 37 introns from 14 genes often rearranged in cancer.

\section{Methods}

\section{Sample collection, p16 staining, and DNA extraction}

Ethical approval for this study was granted by the UCL/ UCLH Ethics Committee (Reference number 04/Q0505/ $59)$ with informed consent obtained where required. Based on the results of a power analysis and taking into account gender and age-matching requirements we selected $20 \mathrm{HPV}+$ and $20 \mathrm{HPV}$ - oropharyngeal carcinomas (from $22 \mathrm{HPV}+$ and $34 \mathrm{HPV}$ - oropharyngeal cancer samples available to us), all formalin fixed paraffin-embedded (Table 1). Our power analysis suggested that by choosing the described number of samples there was a just under $90 \%$ chance of detecting moderate differences in the proportion of mutations between HPV+ and HPV- HNSCC samples $(\mathrm{w}=0.5, P=0.05)$.

Details of sample preparation and selection are illustrated in Figure 1. We confirmed HPV status by p16 staining, and by quantitative PCR for HPV-16 E6, having been shown to have $97 \%$ sensitivity, $94 \%$ specificity, and to be the best discriminator of favorable outcome [6].
Sequencing of HPV DNA demonstrated 100\% concordance of HPV status. All samples were laser-capture microdissected (LCM) to separate tumor epithelial from surrounding stromal tissues, enriching tumor DNA for further analyses. These were processed as $10 \mu \mathrm{m}$ thick unstained slides which were reviewed by an expert pathologist who had marked the slides for tumor subtype enrichment in a corresponding $\mathrm{H} \& \mathrm{E}$ stained section. LCM was carried out on P.A.L.M. MembraneSlide 1.0 PEN slides (Zeiss Microimaging, Munich, Germany) using the Zeiss Palm MicrobeamTM system. Tissue was collected into extraction tubes and processed using the QIAamp DNA FFPE Tissue Kit (Qiagen, Hilden, Germany). Extracted DNA was quantified using a standardized PicoGreen fluorescence assay (LifeTechnologies, Carlsbad, CA, USA).

\section{DNA library construction and hybrid capture}

At least $50 \mathrm{ng}$ and up to $200 \mathrm{ng}$ of extracted DNA was sheared to approximately $100-400$ bp by sonication, followed by end-repair, dA-addition and ligation of indexed, Illumina sequencing adaptors. Sequencing libraries were hybridization captured using RNA-based baits (Agilent), targeting a total of 3,320 exons of 182 cancer-related genes (most commonly altered in cancer, from [7]) plus 37 introns from 14 genes often rearranged in cancer (Additional File 1, Table S1).

Table 1 Patient characteristics of selected HPV+ and HPV- HNSCC samples.

\begin{tabular}{|c|c|c|}
\hline & $\mathrm{HPV}+(n=20)$ & HPV- $(n=20)$ \\
\hline Median age, years (range) & $56.5(42-81)$ & $58(45-77)$ \\
\hline \multirow[t]{2}{*}{ Gender } & M: 14 & M: 14 \\
\hline & $F: 6$ & $F: 6$ \\
\hline Tumor site & Oropharynx: 20 & Oropharynx: 20 \\
\hline \multirow[t]{3}{*}{ Tumor grade } & Well diff: 1 & Well diff: 0 \\
\hline & Mod diff: 9 & Mod diff: 16 \\
\hline & Poorly diff: 10 & Poorly diff: 4 \\
\hline \multirow[t]{5}{*}{ Tumor stage $(\mathrm{T})$} & $\mathrm{T} 1: 5$ & $\mathrm{~T} 1: 1$ \\
\hline & $\mathrm{T} 2: 8$ & T2: 4 \\
\hline & T3: 3 & T3: 5 \\
\hline & $\mathrm{T} 4: 3$ & T4: 10 \\
\hline & N/a: 1 & N/a: 0 \\
\hline \multirow[t]{3}{*}{ Cervical lymph node involvement (N) } & Yes: 16 & Yes:13 \\
\hline & No: 2 & No: 6 \\
\hline & N/a: 2 & N/a: 1 \\
\hline \multirow[t]{3}{*}{ Smoking } & Ever: 9 & Ever: 15 \\
\hline & Never: 8 & Never: 0 \\
\hline & N/a: 3 & N/a: 5 \\
\hline \multirow[t]{4}{*}{ Alcohol } & Heavy drinker (>20U/w): 2 & Heavy drinker (>20U/w): 12 \\
\hline & Occ. alcohol: 5 & Occ. alcohol: 3 \\
\hline & Never: 4 & Never: 0 \\
\hline & N/a: 9 & N/a: 5 \\
\hline
\end{tabular}




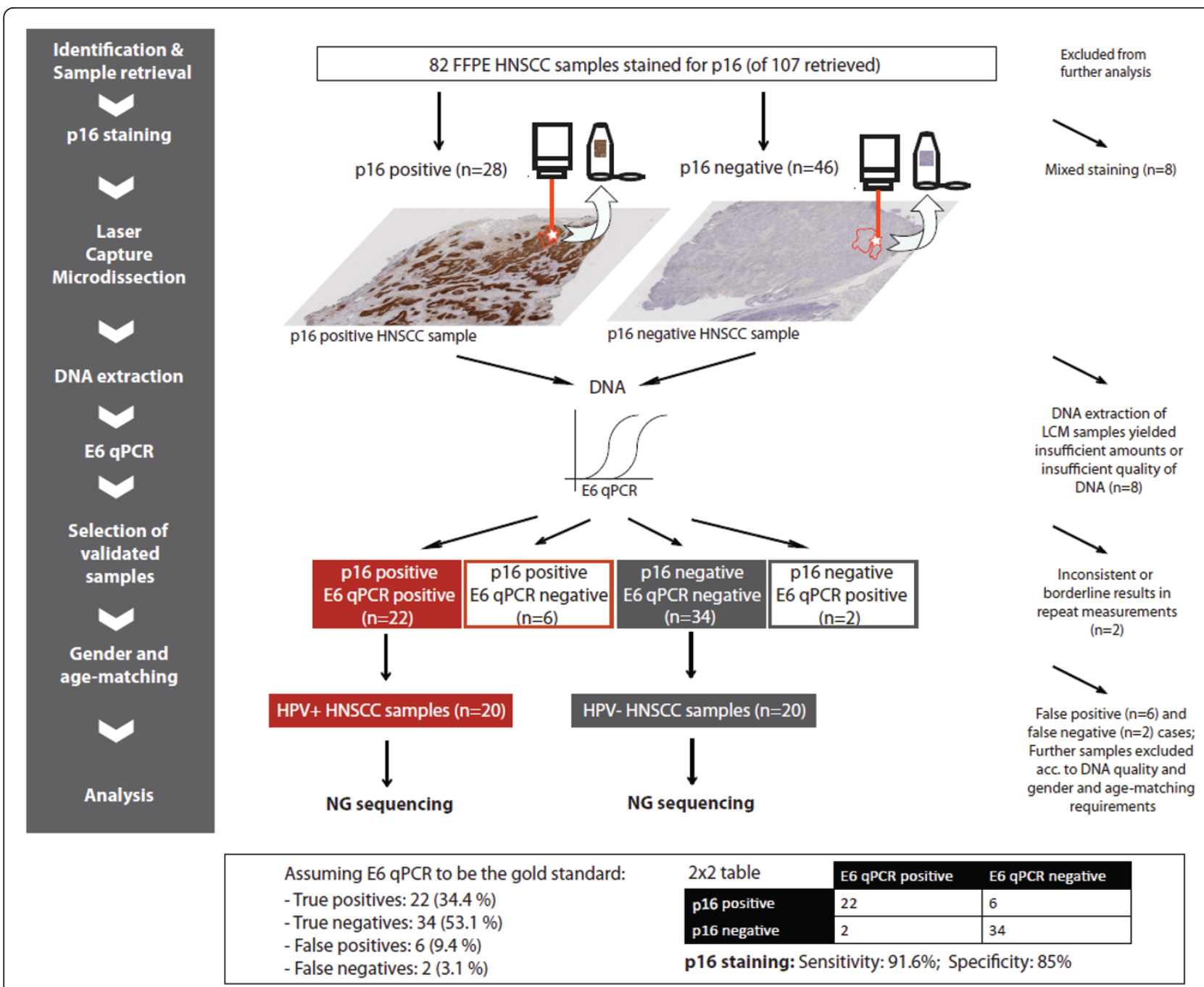

Figure 1 Workflow of FFPE sample preparation and selection. Eighty-two FFPE blocks [19] were stained for p16 of which eight samples were excluded from further analysis, showing mixed p16 staining. Eight samples were excluded after the LCM step, yielding insufficient amounts or quality of DNA and two further samples were excluded due to inconsistent or borderline results in repeat E6 qPCR measurements. In total, 22 confirmed HPV + (p16+ and E6 qPCR+) and 34 HPV- (p16- and E6 qPCR-) samples were suitable for further analysis. Following age and gender matching, 20 HPV+ HNSCC samples (red) and 20 HPV- HNSCC samples (grey) were then selected for the final analysis (next-generation (NG) sequencing).

\section{Sequencing and primary sequence data analysis}

Paired end sequencing $(49 \times 49$ cycles $)$ was performed using the HiSeq2000 (Illumina). Six samples yielded insufficient numbers of reads and were excluded from analysis. The summary of sequencing details is illustrated in Additional File 1, Table S2. Sequence data from gDNA, available from $18 \mathrm{HPV}+$ and $16 \mathrm{HPV}$ - samples, were mapped to the reference human genome (hg19) using the BWA aligner [8]. PCR duplicate read removal and sequence metric collection was performed using Picard [9] and SAMtools [10]. Local alignment optimization was performed using GATK [11]. Hybrid capture reagents included baits designed to capture unique regions of select viral genomes including HPV-16. Sequence read pairs were aligned to the reference genome of the respective viral genomes, and the number of pairs mapping to each viral genome was counted. A total HPV-16 aligned read count of $\geq 5$ reads per million was considered a positive HPV status, and $\leq 2$ negative HPV status.

\section{Genomic alteration detection}

Base substitution detection was performed using a Bayesian methodology, which allows detection of novel somatic mutations at low MAF and increased sensitivity for mutations at hotspot sites [12] through the incorporation of tissue-specific prior expectations: $P\left(\right.$ Mutation present $\mid$ Read data " $\left.R^{\prime \prime}\right)=P\left(\right.$ Frequency of mutation " $\left.\mathrm{F}^{\prime \prime}>0 \mid R\right) \propto 1-P(R \mid F=0) P(F=0)$, where $P(R \mid F)$ is evaluated with a multinomial distribution 
of the observed allele counts using empirically observed error rates and $P(F=0)$ is the prior expectation of mutation in the tumor type. To detect indels, de-novo local assembly in each targeted exon was performed using the de-Bruijn approach [13]. Candidate calls are filtered using a series of quality metrics, including strand bias, read location bias, and a custom database of sequencing artifacts derived from normal controls. Germline alterations are identified and filtered using dbSNP (version 135 [14]) and subsequently annotated for known and likely somatic mutations using the COSMIC database (version 62, http://cancer.sanger.ac.uk/cancergenome/projects/ cosmic/). Detection of copy-number alterations (CNAs) was performed by obtaining a log-ratio profile of the sample by normalizing the sequence coverage obtained at all exons against a process-matched normal control. The profile is segmented and interpreted using allele frequencies of $\sim 1,800$ additional genome-wide SNPs to estimate tumor purity and copy number based on established methods [15-17] by fitting parameters of the equation $l r_{\text {seg }} \sim N\left(\log _{2} \frac{p * C_{\text {seg }}+(1-p) * 2}{p * \text { tumor ploidy }+(1-p) * 2}\right)$, where $l r_{\text {seg }}$, $C_{s e g}$, and $p$ are the log-ratios and copy numbers at each segment and sample purity respectively. Focal amplifications are called at segments with $\geq 6$ copies and homozygous deletions at 0 copies, in samples with purity $>20 \%$.

A summary of known and likely somatic or functional base substitution and indel (short-variant) alterations and of base substitution and indel (short-variant) alterations of unknown status detected by deep sequencing is illustrated in Additional File 1, Table S3 and Additional File 1, Table S4, respectively. A summary of copy number alterations detected by deep sequencing is illustrated in Additional File 1, Table S5.

Validation of selected mutations by Sequenom OncoCarta DNA extracted from FFPE samples were sent to Sequenom (Hamburg, Germany) for blind testing and analysis, using Sequenom OncoCarta panels v1.0 and v3.0, as previously described [18].

\section{Confirmation of copy number changes by Infinium CNA profiling}

Using previously obtained Infinium HumanMethylation 450 BeadChip methylation data on sequenced samples [19], the Bioconductor package 'DNAcopy' [20,21] was applied to calculate the copy number of the majority of sequenced samples, as described previously [22]. All normalized and raw 450k methylation data were submitted to GEO (Gene Expression Omnibus, NCBI) according to instructions provided (GEO accession number: GSE38266).

\section{Immunohistochemistry and interpretation of results}

The sequenced $18 \mathrm{HPV}+$ and $16 \mathrm{HPV}$ - HNSCC samples were stained for PTEN and for Cyclin D1. Staining for these particular targets was chosen as these were already implicated in HNSCC carcinogenesis and validated scoring systems are available [23,24]. Antibody 04-409 (Millipore-Merck KGaA, Darmstadt, Germany) was used for PTEN staining and antibody P2D11F11 (Novocastra) was used Cyclin D1 staining of $10-\mu \mathrm{m}$ thick slides. The stained slides were examined and scored as previously described $[23,24]$ by two experienced histopathologists.

\section{Statistical data analysis}

Significance of enrichment of observed genomic alterations in HPV+ and HPV- HNSCC cases was tested using Pearson's chi-squared test. Relation of gender, tumor site, tumor grade, size of primary tumors (T), lymph node metastasis $(\mathrm{N})$, smoking status, and alcohol intake to the two tested groups was determined using the Wilcoxon rank sum test. Relation of age to the two groups was tested by a logistic regression model. The obtained $P$ values were corrected for multiple testing (FDR adjustment). Correlation of sequencing results with CCND1 and PTEN immunochemistry was tested using Fisher's exact test.

\section{Results}

Patient demographic data

The median age is slightly higher in the HPV-group (58 vs. 56.5 years) (Table 1 ). The male to female ratio is similar between the groups, and the majority of cases show moderately or poorly differentiated histology with evidence of lymph nodal involvement at presentation. In our cohort, as predicted, the vast majority of HPV- cases are in active smokers and/or heavy alcohol users (Table 1 and Figure 2). No significant relationship of gender, tumor site, tumor grade, size of primary tumors $(\mathrm{T})$, lymph node metastasis $(\mathrm{N})$, smoking status, determined using the Wilcoxon rank sum test, to any of the two tested groups (HPV+ HNSCC vs. HPV- HNSCC) was seen. Patients with high alcohol intake were significantly enriched in the HPV-group (Wilcoxon rank sum test; adjusted $P$ value $<0.05$ ).

\section{Next-generation sequencing}

Sequence analysis revealed that HPV+ and HPV- oropharyngeal carcinomas cluster into two distinct subgroups, with few overlapping genetic alterations (Figures 2 and 3). TP53 mutations are detected in 100\% of HPV-samples (Figure 2; significant enrichment in HPV-group; chisquare test, $\mathrm{q}<0.01$ ). The list of observed TP53 mutations is illustrated in Additional File 1, Table S6. CCND1 amplifications (chi-square test, $\mathrm{q}<0.01$ ) and $C D K N 2 A / B$ deletions (chi-square test, $\mathrm{q}<0.05$ ) were exclusively 


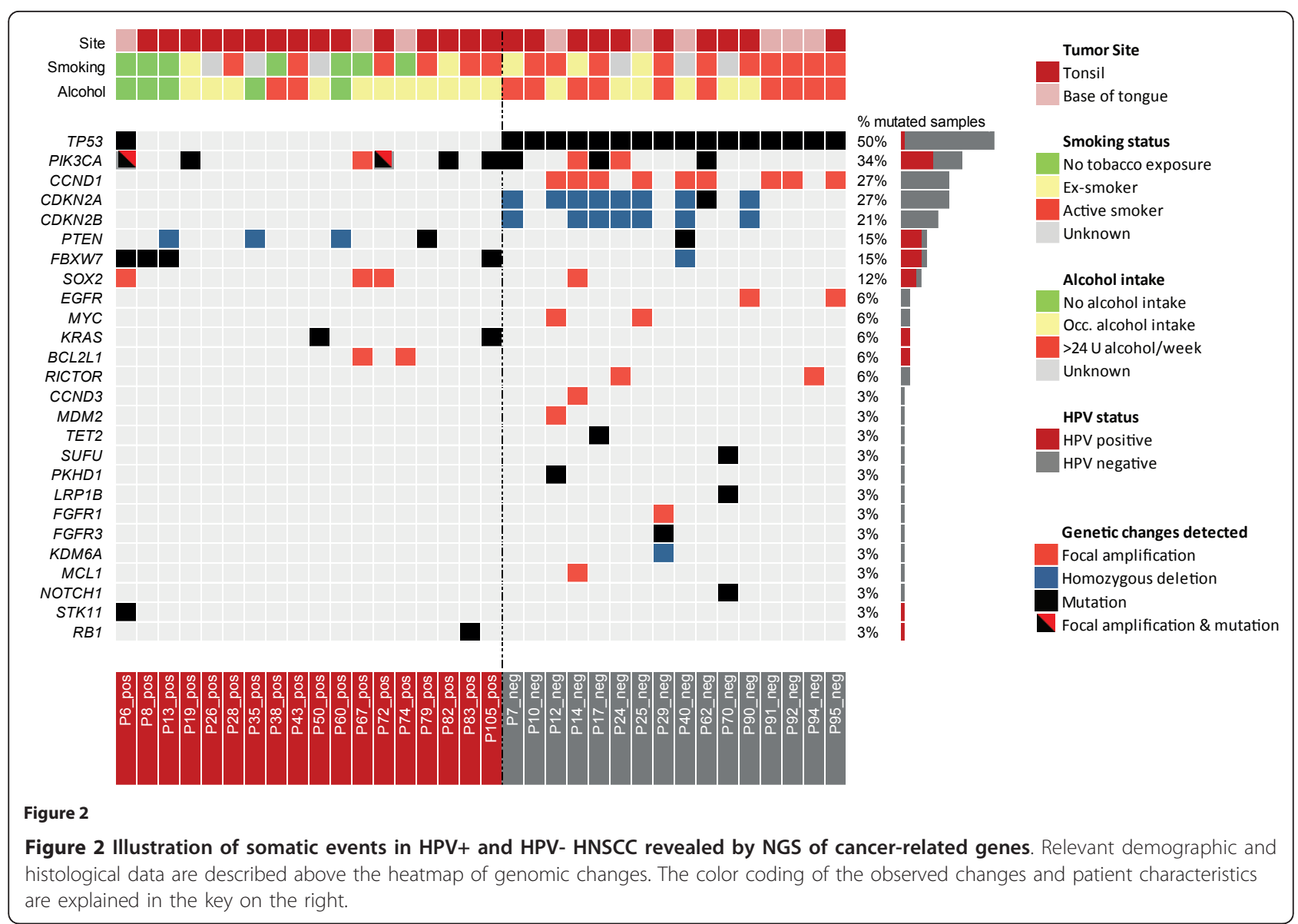

detected in HPV - cases (in approximately 55\% and 40\% of cases). PIK3CA mutation or amplification, and PTEN inactivation by gene copy loss or mutation were seen in $>55 \%$ of HPV + tumors, and in 31\% HPV-tumors. FBXW7 alterations were present in $>15 \%$ of all samples and SOX2 amplification in $12 \%$ of cases.

\section{Validation of obtained results}

For validation of our results, we applied Infinium CNA profiling, Sequenom OncoCarta panels v1.0 and v3.0 and immunohistochemistry. Copy number gains and losses detected by next-generation sequencing (NGS) were interrogated by Infinium CNA profiling (Additional File 2, Figure S1). Forty-eight of fifty (96\%) copy number alterations detected by sequencing were confirmed (Figure 4). Furthermore, the detected mutations by NGS were validated by Sequenom OncoCarta panels v1.0 and v3.0 (Additional File 2, Figure S2). As our NGS technique targeted the whole gene sequence, whereas Sequenom OncoCarta panels only target specific mutational hotspots of certain genes, the majority of NGS detected mutations were not included in the Sequenom analysis. Eight out of nine mutations that were detected by NGS were also confirmed by Sequenom. One PIK3CA mutation in sample P72_pos was called at $1 \%$ allele frequency by NGS, and this mutation was therefore unlikely to be detected by Sequenom analysis.

For CCND1 and PTEN we also validated findings by immunohistochemistry in sample material from the $18 \mathrm{HPV}+$ and 16 HPV- HNSCC samples tested by NGS. Genomic alterations in CCND1 were confirmed by Cyclin D1 immunochemistry with strong expression of Cyclin D1 protein in eight of nine CCND1 amplified cases (and intermediate expression in the remaining case). Using all tested samples, significant correlation of CCND1 sequencing results with Cyclin D1 immunochemistry was observed $(P=7.34 \mathrm{e}-05$; Fisher's exact test). Representative samples are shown in Figure 5. PTEN loss and mutation were validated by immunohistochemistry (Figure 6). PTEN staining was negative in all cases in which NGS revealed a homozygous deletion or mutation. Four additional samples displayed low PTEN protein expression. In three of these cases a heterozygous deletion/single copy loss of PTEN was present, as detected by NGS. In the remaining sample other mechanisms may 

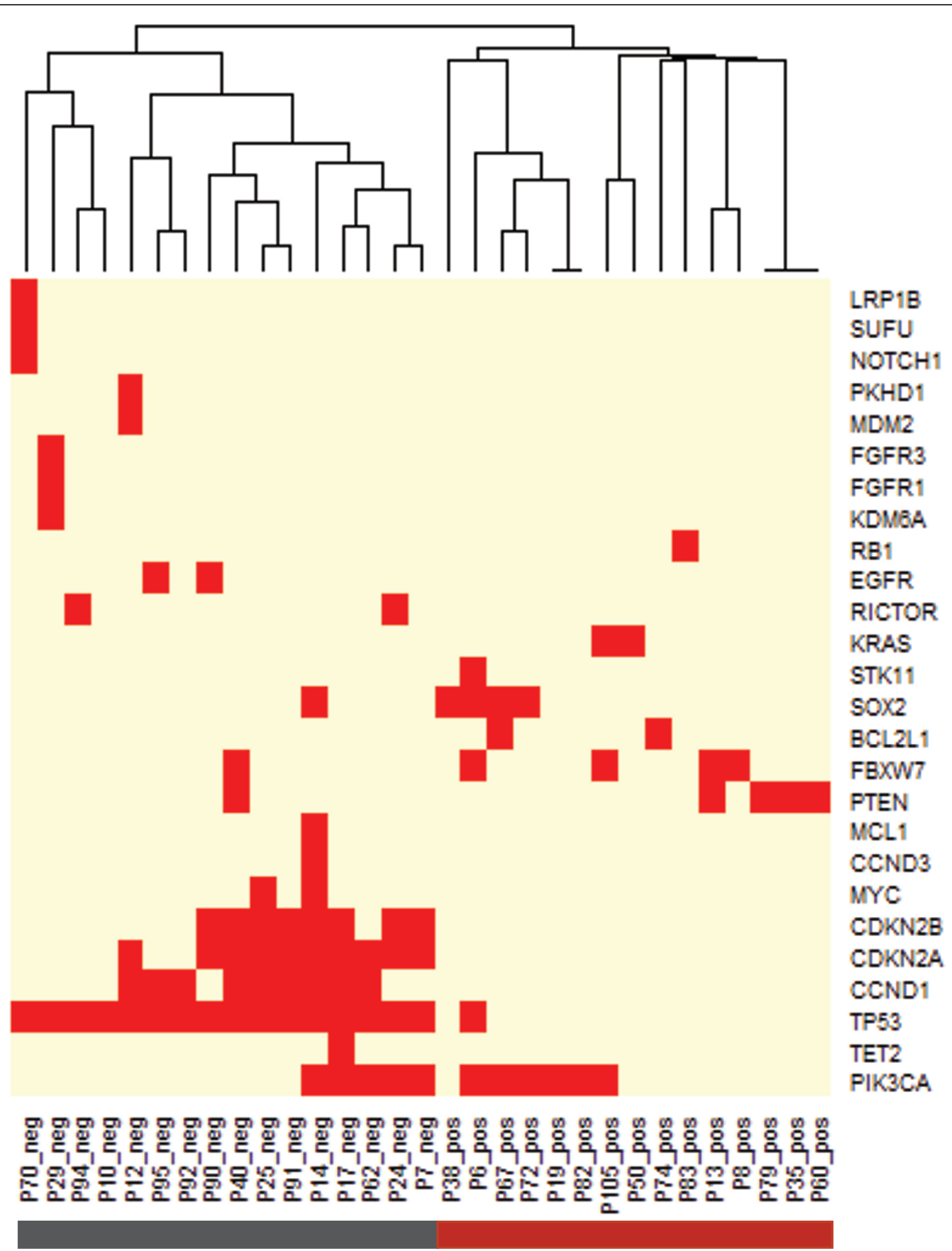

Figure 3 Hierarchical clustering of HPV+ and HPV- HNSCC samples using all detected genetic changes. HPV+ and HPV- HNSCC samples clustered in $100 \%$ of cases.

explain the loss of expression, such as an epigenetic alteration or changes in the post-transcriptional regulation of PTEN. Overall highly significant correlation of PTEN sequencing results with PTEN immunochemistry was demonstrated ( $P=0.0009$; Fisher's exact test).
Mutations reported in this study as 'known somatic' were limited to those that have been previously confirmed to be somatic in other tumors, through sequencing of matched normal specimens. Consequently, we are confident that these alterations are somatic. 


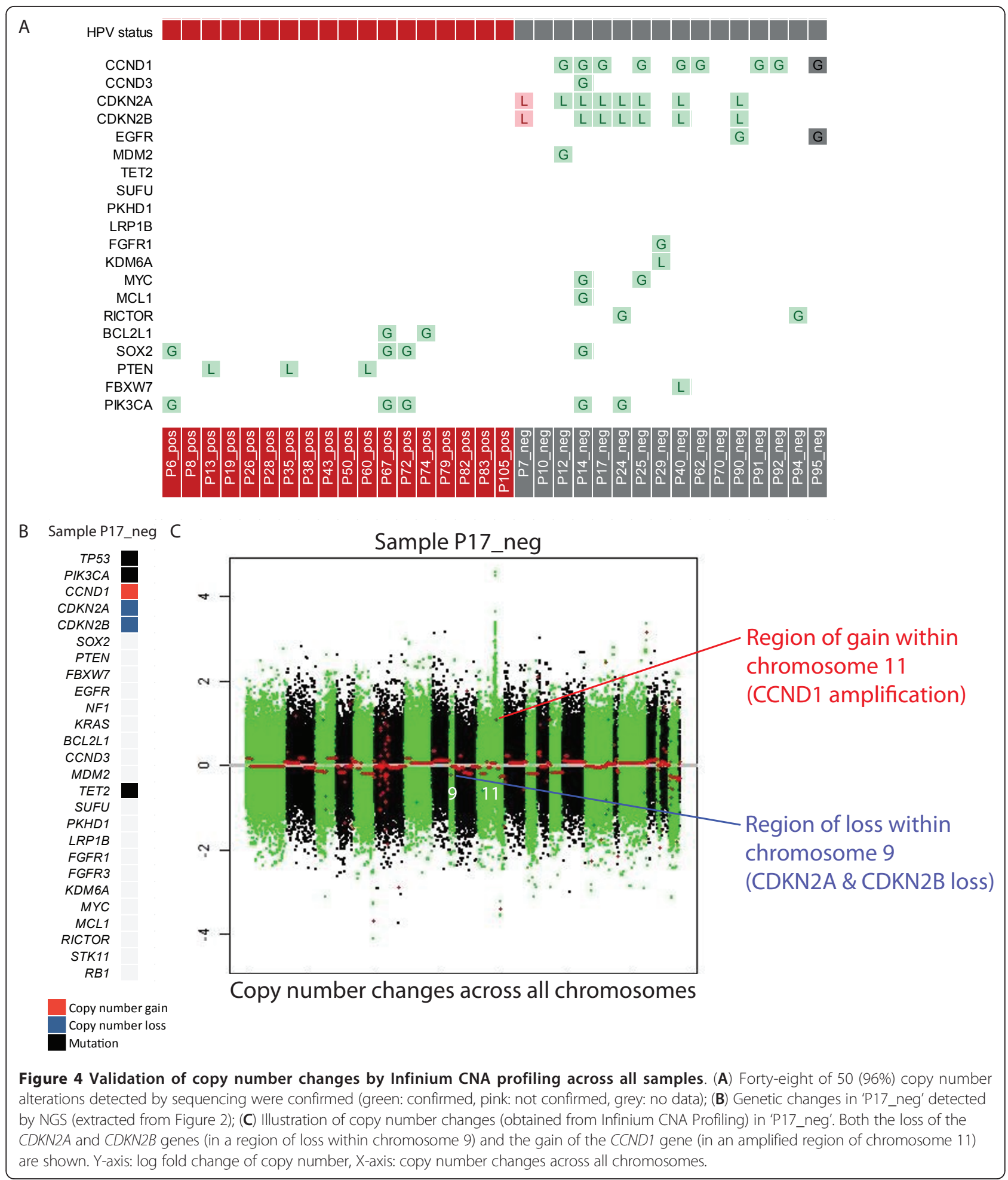

\section{Discussion}

Overall, sequence analysis revealed that HPV+ and HPVoropharyngeal carcinomas cluster into two distinct subgroups, with few overlapping genetic alterations. These data concur with epidemiological and clinical data, indicating that HPV+ HNSCC is a distinct disease entity $[25,26]$.

Our detection of TP53 mutations in 100\% of HPVsamples, higher than previously reported [27], suggests that our approach of laser capture microdissection coupled 

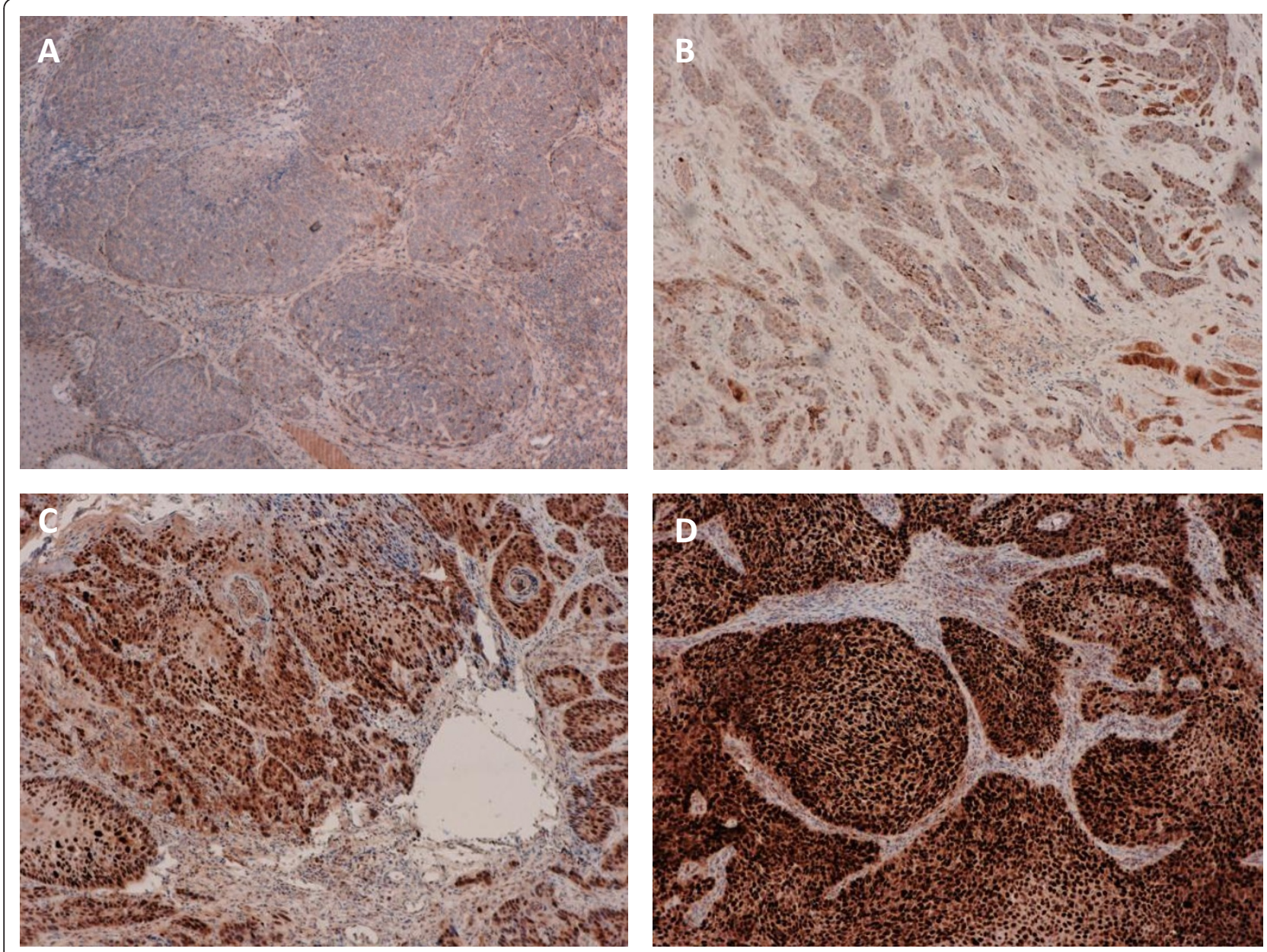

Figure 5 Validation of detected copy number alterations of Cyclin D1 (CCND1) by immunohistochemistry. Staining of HNSCC samples for Cyclin D1 confirmed strong expression in eight of nine CCND1 amplified cases (and intermediate expression in the remaining case) compared with samples harboring no copy number alteration; Representative samples shown: Low levels of CCND1 expression in the tumor tissue of sample 'P38_pos' (A) and sample 'P29_neg' (B); NGS: No CNA; High levels of Cyclin D1 expression in the tumor tissue of sample 'P12_neg' (C) and sample 'P17_neg' (D); NGS: CCND1 copy number gain.

with targeted deep sequencing is a highly sensitive method by which to assay specific tumor mutations. Taken together with the fact that in the HPV+ tumors, p53 function is suppressed by E6, our data suggest an obligate requirement for $\mathrm{p} 53$ abrogation in oropharyngeal tumorigenesis. One caveat in our study is that all HPV- samples analyzed were also p16 negative, thus it remains possible that in HPV- samples with elevated p16 expression (for example, through $R B 1$ mutation), the frequency of TP53 mutation is $<100 \%$.

We identified only one TP53 mutation in an HPV+ tumor. However, this mutation (R290C, Additional File 1, Table S2) causes only a $40 \%$ decrease in TP53 function and has been detected in sarcomas harboring MDM2 amplification $[28,29]$.

Our data for HPV- oropharyngeal cancer indicate that the frequency of CCND1 amplification (in approximately
$55 \%$ of cases) and $C D K N 2 A / B$ deletions (in approximately $55 \%$ of cases) are higher than previously reported [30]. CCND1 amplification has also been described in $12 \%$ of non-small cell lung cancers [31] and in up to $41 \%$ of esophageal squamous cell carcinomas [32], suggesting that this could be one of the more common genetic alterations linked to smoking-induced epithelial malignancy. In HPV + cancer, the oncoprotein E7 leads to cell cycle dysregulation by substituting for cyclin D gain-of-function and cyclin dependent kinase inhibitor loss-of-function activities. Overall, this indicates that direct dysregulation of the cell cycle is a key mechanism for oropharyngeal tumors to evolve.

HPV+ HNSCC samples frequently harbor mutations or CNAs in genes implicated in activation of the PI3K/AKT/ mTOR pathway. In particular, PIK3CA mutation and PTEN inactivation by gene copy loss or mutation were 

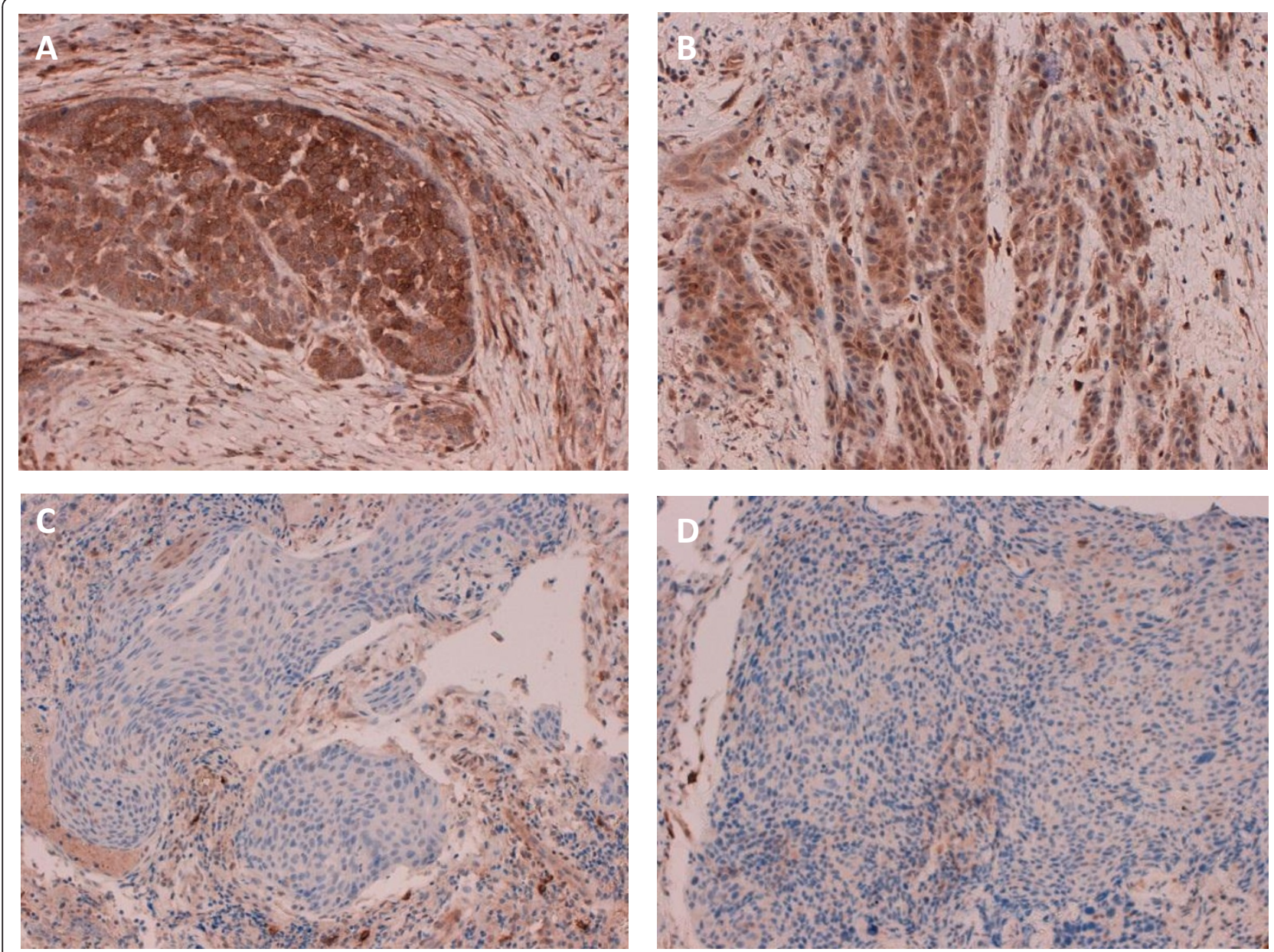

Figure 6 Validation of detected PTEN copy number loss by immunohistochemistry. Staining of HNSCC samples for PTEN was negative in all cases in which deep sequencing revealed a homozygous deletion or mutation. Representative samples shown: Abundant PTEN expression in the tumor tissue of sample 'P26_pos' (A) and sample 'P70_neg' (B); Deep-sequencing: No CNA; Absence of PTEN protein in the tumor tissue of sample 'P60_pos' (C) and sample 'P13_pos' (D); Deep-sequencing: PTEN copy number loss.

seen in $>60 \%$ of HPV+ tumors, and in $31 \% \mathrm{HPV}$ - tumors. There is a significant relation between PIK3CA and PTEN, and HPV status; chi-square test, $P<0.001$. These findings may help to explain the high frequency of PI3K pathway activation in HPV+ HNSCC samples and the efficacy of mTOR inhibitors in xenograft studies with HPV+ cell lines previously reported [33]. It will be important to audit both the sequence and copy number of the PIK3CA and PTEN genes if such agents are tested in clinical trials for HPV-associated HNSCC.

Our results suggest that mutations in $F B X W 7$ may be enriched in HPV+ disease. FBXW7 is an E3 ubiquitin ligase that targets a number of growth-promoting proteins for proteasomal degradation, including Cyclin E, MYC, NOTCH and mTOR $[34,35]$. Loss of FBXW7 occurs in combination with $\mathrm{NOTCH}$ gain-of-function mutations in T-ALL [36], suggesting it may be an important target for FBXW7 ligase activity in these tumors. In contrast,
HNSCC frequently display NOTCH loss-of-functionmutations [37,38], thus in HNSCC, other substrates such as Cyclin E, MYC, or mTOR may be the relevant targets for FBXW7. We found one HPV- sample harboring a NOTCH1 mutation, concurring with previous studies reporting NOTCH1 mutations in HNSCC $[4,5]$.

Two of our tested HPV+ samples harbored KRAS mutations. KRAS mutations have been associated with a history of smoking [39]. One of the patients was a smoker and in the other one the smoking status was unknown. HRAS mutations were not detected in any of our tested samples. In previous studies, mutations in the HRAS gene were mainly detected in oral cavity cancer samples $[4,5]$.

The SOX2 and PIK3CA genes both reside on the long arm of chromosome 3 (3q26) and these genes were amplified in three HPV+ samples and one HPV- tumor. While PIK3CA amplifications have previously been reported in HPV+ HNSCC [40,41], SOX2 has recently been proposed 
as the critical target of 3q gains observed at a high frequency in squamous lung cancer [42] and in esophageal squamous cell carcinoma [43]. SOX2 is also frequently amplified and overexpressed in oral squamous cell carcinoma [44]. Furthermore, SOX2 expression is upregulated in a subpopulation of putative HNSCC stem cells that displays characteristics of epithelial to mesenchymal transition (EMT), associated with increased propensity for metastasis [45].

We also demonstrate for the first time inactivating mutations in STK11 in HPV+ HNSCC. Loss of STK11 is associated with metastasis in head and neck cancer [46]. Furthermore, loss of function mutations in STK11 (LKB1) result in activation of $\mathrm{mTORC1}$ signaling and can sensitize cells to mTOR inhibition [47,48]. Mutations in these genes therefore (in addition to PIK3CA and PTEN) warrant evaluation as potential determinants of sensitivity to mTOR inhibitors currently in clinical trials for HNSCC [49].

Beyond the genes directly involved in signaling and cell cycle, we found amplifications in genes implicated in preventing apoptosis: BCL2L1 (6\% amplification) and MCL1 (3\% amplification), suggesting that direct suppression of apoptosis may also contribute to HNSCC pathogenesis.

Receptor tyrosine kinase mutations, FGFR1, FGFR3, and $E G F R$, were only observed in HPV-tumors at low frequency.

Overall, our data strongly support a causal role for HPV in oropharyngeal carcinogenesis by overcoming the requirement for genetic lesions in the TP53 and RB1 tumor suppressor pathways evident in the HPV- tumors. Our detection of frequent PI3K/AKT/mTOR pathway alterations in HPV+ tumors is consistent with a recent report demonstrating PI3K pathway activation and sensitivity to mTOR inhibition in both cervical carcinoma and HPV+ HNSCC [33]. Together, these studies provide a rationale for the testing of PI3K pathway inhibitors in HPV+ HNSCC. In $\mathrm{HPV}$ - tumors, the frequent alteration of $C D K N 2 A / B$ and/or $C C N D 1$ suggests that, if supported by functional data, trials with CDK inhibitors may be indicated. Our data support the observations by gene expression microarrays and by genome-wide methylation studies that HPV+ HNSCC is a distinct entity, with a distinct set of somatic alterations. However, it would appear that a core set of pathways (TP53, RB1/cell cycle, and PI3K/AKT/mTOR) is compromised in both HPV+ and HPV- oropharyngeal tumors, thus targeted therapies directed against one or more of these pathways could be efficacious in both contexts.

\section{Additional material}

Additional file 1: Table S1: 182 genes sequenced across entire coding sequence $(A)$ and 14 genes sequenced across selected introns (B). Table S2: Summary of sequencing details for study samples. Table S3: Summary of known and likely somatic or functional base substitution and indel (short-variant) alterations detected by deep sequencing. Table S4: Summary of base substitution and indel (shortvariant) alterations of unknown status detected by deep sequencing. Table S5: Summary of copy number alterations detected by deep sequencing. Table S6: List of TP53 mutations revealed by deep sequencing in HPV+ and HPV- HNSCC samples.

Additional file 2: Figure S1: Infinium CNA profiling of HPV+ and HPV- HNSCC samples. Obtained genome-wide copy number alteration profiles (cumulative frequencies) between the two groups are illustrated and chromosomes displaying similar patterns of gain and loss in HPV+ and HPV- HNSCC samples are boxed. Chromosome 6 (MHC regions) and Y chromosome are not shown. Figure S2: Validation of detected mutations by SequenomOncoCarta panels v1.0 and v3.0. Mutations in HNSCC samples detected by deep sequencing were validated using the OncoCartapanels $v 1.0$ and v3.0. 8 out of 9 mutations that were successfully tested on the Oncocarta panel were confirmed (green: confirmed, pink: not confirmed, grey: $\mathrm{n} / \mathrm{a}$ ). *The PIK3CA_E545K mutation in sample P72_pos was called at $1 \%$ allele frequency by NGS, and this mutation was therefore unlikely to be detected by Sequenom analysis.

\section{Abbreviations}

CNA: Copy number alteration; EMT: epithelial to mesenchymal transition; FF: fresh-frozen; FFPE: formalin-fixed paraffin-embedded; GEO: Gene Expression Omnibus; HNSCC: head and neck squamous cell cancer; HPV: human papillomavirus; HPV+: HPV positive; HPV-: HPV negative; LCM: laser-capture microdissected; NGS: next-generation sequencing; PI3K: PI3 kinase.

\section{Competing interests}

NGS of samples was in collaboration with Foundation Medicine. Employees of Foundation Medicine: GF, MTC, DL, VAM, RY, PJS

\section{Authors' contributions}

All authors contributed to the interpretation of data and to the writing of the manuscript. In detail: Study design and conceptualization of study: ML, GF, TF, GP, SB, CB; Sample preparation, tumor collection, and technical work: ML, GF, TF, MF, FV, PO'F, NK; Histology and Computational Biology: AJ, AF, TAB, RY, NP, PJS; Figures and Tables: ML, GF, TF, AF. All authors read and approved the final manuscript.

\section{Acknowledgements}

We would like to thank Keith Miller, Mike Gandy, and Philippa Jones from UCL Advanced Diagnostics and Dr. Geoff Boxer, George Chennell (UCL Genomics), and the teams at the Head and Neck Centre and the Department of Histopathology at University College London Hospitals (UCLH) for advice and technical support.

This study was supported by the UCLH/UCL NIHR Biomedical Research Centre (BRC) and ML was supported by a Wellcome Trust Fellowship (WT093855MA) and by the Austrian Science Fund (J2856). SB was supported by the Wellcome Trust (WT084071) and a Royal Society Wolfson Research Merit Award (WM100023). The CB Laboratory is supported by Cancer Research U.K.

\section{Authors' details}

${ }^{1}$ UCL Cancer Institute, University College London, 72 Huntley Street, London, WC1E 6BT, UK. ${ }^{2}$ Head and Neck Centre, University College London Hospitals NHS Trust, Euston Road, London, NW1 2PG, UK. ${ }^{3}$ Foundation Medicine, One Kendall Square, Suite B3501, Cambridge, MA 02139, USA. ${ }^{4}$ Department of Histopathology, University College London Hospitals NHS Trust, Rockefeller Building, University Street, London, WC1E 6JJ, UK.

Received: 20 February 2013 Revised: 15 April 2013 Accepted: 29 May 2013 Published: 29 May 2013

\section{References}

1. Chaturvedi AK, Engels EA, Pfeiffer RM, Hernandez BY, Xiao W, Kim E, Jiang B, Goodman MT, Sibug-Saber M, Cozen W, Liu L, Lynch CF, Wentzensen N, Jordan RC, Altekruse S, Anderson WF, Rosenberg PS, Gillison ML: Human 
papillomavirus and rising oropharyngeal cancer incidence in the United States. J Clin Oncol 2011, 29:4294-4301.

2. Mendenhall WM, Logan HL: Human papillomavirus and head and neck cancer. Am J Clin Oncol 2009, 32:535-539.

3. Fakhry C, Westra WH, Li S, Cmelak A, Ridge JA, Pinto H, Forastiere A, Gillison ML: Improved survival of patients with human papillomaviruspositive head and neck squamous cell carcinoma in a prospective clinical trial. J Natl Cancer Inst 2008, 100:261-269.

4. Agrawal N, Frederick MJ, Pickering CR, Bettegowda C, Chang K, Li RJ, Fakhry C, Xie TX, Zhang J, Wang J, Zhang N, El-Naggar AK, Jasser SA, Weinstein JN, Trevino L, Drummond JA, Muzny DM, Wu Y, Wood LD, Hruban RH, Westra WH, Koch WM, Califano JA, Gibbs RA, Sidransky D, Vogelstein B, Velculescu VE, Papadopoulos N, Wheeler DA, Kinzler KW, et al: Exome sequencing of head and neck squamous cell carcinoma reveals inactivating mutations in NOTCH1. Science 2011, 333:1154-1157.

5. Stransky N, Egloff AM, Tward AD, Kostic AD, Cibulskis K, Sivachenko A, Kryukov GV, Lawrence MS, Sougnez C, McKenna A, Shefler E, Ramos AH, Stojanov P, Carter SL, Voet D, Cortes ML, Auclair D, Berger MF, Saksena G, Guiducci C, Onofrio RC, Parkin M, Romkes M, Weissfeld JL, Seethala RR, Wang L, Rangel-Escareno C, Fernandez-Lopez JC, Hidalgo-Miranda A, Melendez-Zajgla J, et al: The mutational landscape of head and neck squamous cell carcinoma. Science 2011, 333:1157-1160.

6. Schache AG, Liloglou T, Risk JM, Filia A, Jones TM, Sheard J, Woolgar JA, Helliwell TR, Triantafyllou A, Robinson M, Sloan P, Harvey-Woodworth C, Sisson D, Shaw RJ: Evaluation of human papilloma virus diagnostic testing in oropharyngeal squamous cell carcinoma: sensitivity, specificity, and prognostic discrimination. Clin Cancer Res 2011, 17:6262-6271.

7. [http://www.sanger.ac.uk/genetics/CGP/cosmic/]

8. Li H, Durbin R: Fast and accurate short read alignment with BurrowsWheeler transform. Bioinformatics 2009, 25:1754-1760.

9. [http://picard.sourceforge.net].

10. Li H, Handsaker B, Wysoker A, Fennell T, Ruan J, Homer N, Marth G, Abecasis G, Durbin R: The Sequence Alignment/Map format and SAMtools. Bioinformatics 2009, 25:2078-2079.

11. DePristo MA, Banks E, Poplin R, Garimella KV, Maguire JR, Hartl C, Philippakis AA, del Angel G, Rivas MA, Hanna M, McKenna A, Fennell TJ, Kernytsky AM, Sivachenko AY, Cibulskis K, Gabriel SB, Altshuler D, Daly MJ: A framework for variation discovery and genotyping using nextgeneration DNA sequencing data. Nat Genet 2011, 43:491-498.

12. Forbes SA, Bindal N, Bamford S, Cole C, Kok CY, Beare D, Jia M, Shepherd R, Leung K, Menzies A, Teague JW, Campbell PJ, Stratton MR, Futreal PA: COSMIC: mining complete cancer genomes in the Catalogue of Somatic Mutations in Cancer. Nucleic Acids Res 2011, 39:D945-950.

13. Compeau PE, Pevzner PA, Tesler G: How to apply de Bruijn graphs to genome assembly. Nat Biotechnol 2011, 29:987-991.

14. [http://www.ncbi.n/m.nih.gov/projects/SNP/].

15. Carter SL, Cibulskis K, Helman E, McKenna A, Shen H, Zack T, Laird PW, Onofrio RC, Winckler W, Weir BA, Beroukhim R, Pellman D, Levine DA, Lander ES, Meyerson M, Getz G: Absolute quantification of somatic DNA alterations in human cancer. Nat Biotechnol 2012, 30:413-421.

16. Van Loo P, Nordgard SH, Lingjaerde OC, Russnes HG, Rye IH, Sun W, Weigman VJ, Marynen P, Zetterberg A, Naume B, Perou CM, BorresenDale AL, Kristensen VN: Allele-specific copy number analysis of tumors. Proc Natl Acad Sci USA 2010, 107:16910-16915.

17. Yau C, Mouradov D, Jorissen RN, Colella S, Mirza G, Steers G, Harris A, Ragoussis J, Sieber O, Holmes CC: A statistical approach for detecting genomic aberrations in heterogeneous tumor samples from single nucleotide polymorphism genotyping data. Genome Biol 2010, 11:R92.

18. Fumagalli D, Gavin PG, Taniyama Y, Kim SI, Choi HJ, Paik S, Pogue-Geile KL: A rapid, sensitive, reproducible and cost-effective method for mutation profiling of colon cancer and metastatic lymph nodes. BMC Cancer 2010, 10:101.

19. Lechner M, Fenton T, West J, Wilson G, Feber A, Henderson S, Thirlwell C, Dibra HK, Jay A, Butcher L, Chakravarthy AR, Gratrix F, Patel N, Vaz F, O'Flynn P, Kalavrezos N, Teschendorff AE, Boshoff C, Beck S: Identification and functional validation of HPV-mediated hypermethylation in head and neck squamous cell carcinoma. Genome Med 2013, 5:15.

20. [http://bioc.ism.ac.jp/2.10/bioc/html/DNAcopy.html].
21. Venkatraman $E S$, Olshen $A B: A$ faster circular binary segmentation algorithm for the analysis of array CGH data. Bioinformatics 2007, 23:657-663.

22. Feber $A$, Guilhamon $P$, Lechner $M$, Fenton $T$, Wilson GA, Thirlwell $C$, Flanagan AM, Teschendorff AE, Kelly JD, Beck S: CNA profiling using highdensity DNA methylation arrays. Genome Biol 2013, In revision.

23. Djordjevic B, Hennessy BT, Li J, Barkoh BA, Luthra R, Mills GB, Broaddus RR: Clinical assessment of PTEN loss in endometrial carcinoma: immunohistochemistry outperforms gene sequencing. Mod Pathol 2012, 25:699-708.

24. Reis-Filho JS, Savage K, Lambros MB, James M, Steele D, Jones RL, Dowsett M: Cyclin D1 protein overexpression and CCND1 amplification in breast carcinomas: an immunohistochemical and chromogenic in situ hybridisation analysis. Mod Pathol 2006, 19:999-1009.

25. Gillison ML: Human papillomavirus-associated head and neck cancer is a distinct epidemiologic, clinical, and molecular entity. Semin Oncol 2004, 31:744-754.

26. Gillespie MB, Rubinchik S, Hoel B, Sutkowski N: Human papillomavirus and oropharyngeal cancer: what you need to know in 2009. Curr Treat Options Oncol 2009, 10:296-307.

27. Leemans CR, Braakhuis BJ, Brakenhoff RH: The molecular biology of head and neck cancer. Nat Rev Cancer 2011, 11:9-22.

28. Ito M, Barys L, O'Reilly T, Young S, Gorbatcheva B, Monahan J, ZumsteinMecker S, Choong PF, Dickinson I, Crowe P, Hemmings C, Desai J, Thomas DM, Lisztwan J: Comprehensive mapping of p53 pathway alterations reveals an apparent role for both SNP309 and MDM2 amplification in sarcomagenesis. Clin Cancer Res 2011, 17:416-426.

29. Petitjean A, Mathe E, Kato S, Ishioka C, Tavtigian SV, Hainaut P, Olivier M: Impact of mutant p53 functional properties on TP53 mutation patterns and tumor phenotype: lessons from recent developments in the IARC TP53 database. Hum Mutat 2007, 28:622-629.

30. Gollin SM: Chromosomal alterations in squamous cell carcinomas of the head and neck: window to the biology of disease. Head Neck 2001, 23:238-253.

31. Cerami E, Gao J, Dogrusoz U, Gross BE, Sumer SO, Aksoy BA, Jacobsen A, Byrne CJ, Heuer ML, Larsson E, Antipin Y, Reva B, Goldberg AP, Sander C, Schultz N: The cBio cancer genomics portal: an open platform for exploring multidimensional cancer genomics data. Cancer Discov 2012, 2:401-404

32. Wang MT, Chen G, An SJ, Chen ZH, Huang ZM, Xiao P, Ben XS, Xie Z, Chen SL, Luo DL, Tang JM, Lin JY, Zhang XC, Wu YL: Prognostic significance of cyclinD1 amplification and the co-alteration of cyclinD1/ $\mathrm{pRb} / \mathrm{ppRb}$ in patients with esophageal squamous cell carcinoma. Dis Esophagus 2012, 25:664-670.

33. Molinolo AA, Marsh C, El Dinali M, Gangane N, Jennison K, Hewitt S, Patel V, Seiwert TY, Gutkind JS: mTOR as a molecular target in HPV-associated oral and cervical squamous carcinomas. Clin Cancer Res 2012. 18:2558-2568.

34. Schulein C, Eilers M, Popov N: PI3K-dependent phosphorylation of Fbw7 modulates substrate degradation and activity. FEBS Lett 2011, 585:2151-2157.

35. Siu KT, Rosner MR, Minella AC: An integrated view of cyclin E function and regulation. Cell Cycle 2012, 11:57-64.

36. Kox C, Zimmermann M, Stanulla M, Leible S, Schrappe M, Ludwig WD, Koehler R, Tolle G, Bandapalli OR, Breit S, Muckenthaler MU, Kulozik AE: The favorable effect of activating NOTCH1 receptor mutations on long-term outcome in T-ALL patients treated on the ALL-BFM 2000 protocol can be separated from FBXW7 loss of function. Leukemia 2010, 24:2005-2013.

37. Stransky N, Egloff AM, Tward AD, Kostic AD, Cibulskis K, Sivachenko A, Kryukov GV, Lawrence M, Sougnez C, McKenna A, Shefler E, Ramos AH, Stojanov P, Carter SL, Voet D, Cortes ML, Auclair D, Berger MF, Saksena G, Guiducci C, Onofrio R, Parkin M, Romkes M, Weissfeld JL, Seethala RR, Wang L, Rangel-Escareno C, Fernandez-Lopez JC, Hidalgo-Miranda A, Melendez-Zajgla J, et al: The mutational landscape of head and neck squamous cell carcinoma. Science 2011, 333:1157-1160.

38. Agrawal N, Frederick MJ, Pickering CR, Bettegowda C, Chang K, Li RJ, Fakhry C, Xie TX, Zhang J, Wang J, Zhang N, El-Naggar AK, Jasser SA, Weinstein JN, Trevino L, Drummond JA, Muzny DM, Wu Y, Wood LD, Hruban RH, Westra WH, Koch WM, Califano JA, Gibbs RA, Sidransky D, Vogelstein B, Velculescu VE, Papadopoulos N, Wheeler DA, Kinzler KW, et al: 
Exome sequencing of head and neck squamous cell carcinoma reveals inactivating mutations in NOTCH1. Science 2011, 333:1154-1157.

39. Thunnissen FB, Prinsen C, Hol B, Van der Drift M, Vesin A, Brambilla C, Montuenga L, Field JK: Smoking history and lung carcinoma: KRAS mutation is an early hit in lung adenocarcinoma development. Lung Cancer 2012, 75:156-160.

40. Redon R, Muller D, Caulee K, Wanherdrick K, Abecassis J, du Manoir S: A simple specific pattern of chromosomal aberrations at early stages of head and neck squamous cell carcinomas: PIK3CA but not p63 gene as a likely target of 3q26-qter gains. Cancer Res 2001, 61:4122-4129.

41. Yarbrough WG, Whigham A, Brown B, Roach M, Slebos R: Phosphoinositide kinase-3 status associated with presence or absence of human papillomavirus in head and neck squamous cell carcinomas. Int I Radiat Oncol Biol Phys 2007, 69:S98-101.

42. McCaughan F, Pole JC, Bankier AT, Konfortov BA, Carroll B, Falzon M, Rabbitts TH, George PJ, Dear PH, Rabbitts PH: Progressive 3q amplification consistently targets SOX2 in preinvasive squamous lung cancer. Am J Respir Crit Care Med 2010, 182:83-91.

43. Gen Y, Yasui K, Zen Y, Zen K, Dohi O, Endo M, Tsuji K, Wakabayashi N, Itoh Y, Naito Y, Taniwaki M, Nakanuma Y, Okanoue T, Yoshikawa T: SOX2 identified as a target gene for the amplification at $3 q 26$ that is frequently detected in esophageal squamous cell carcinoma. Cancer Genet Cytogenet 2010, 202:82-93.

44. Freier K, Knoepfle K, Flechtenmacher C, Pungs S, Devens F, Toedt G, Hofele C, Joos S, Lichter P, Radlwimmer B: Recurrent copy number gain of transcription factor SOX 2 and corresponding high protein expression in oral squamous cell carcinoma. Genes Chromosomes Cancer 2010, 49:9-16.

45. Chen C, Wei Y, Hummel M, Hoffmann TK, Gross M, Kaufmann AM, Albers AE: Evidence for epithelial-mesenchymal transition in cancer stem cells of head and neck squamous cell carcinoma. PLoS One 2011, 6: e16466.

46. Kline ER, Muller S, Pan L, Tighiouart M, Chen ZG, Marcus Al: Localizationspecific LKB1 loss in head and neck squamous cell carcinoma metastasis. Head Neck 2011, 33:1501-1512.

47. Corradetti MN, Inoki K, Bardeesy N, DePinho RA, Guan KL: Regulation of the TSC pathway by LKB1: evidence of a molecular link between tuberous sclerosis complex and Peutz-Jeghers syndrome. Genes Dev 2004, 18:1533-1538.

48. Shaw RJ, Bardeesy N, Manning BD, Lopez L, Kosmatka M, DePinho RA, Cantley LC: The LKB1 tumor suppressor negatively regulates mTOR signaling. Cancer Cell 2004, 6:91-99.

49. Nguyen SA, Walker D, Gillespie MB, Gutkind JS, Day TA: mTOR inhibitors and its role in the treatment of head and neck squamous cell carcinoma. Curr Treat Options Oncol 2012, 13:71-81.

\section{doi:10.1186/gm453}

Cite this article as: Lechner et al:: Targeted next-generation sequencing of head and neck squamous cell carcinoma identifies novel genetic alterations in HPV+ and HPV- tumors. Genome Medicine 2013 5:49.

\section{Submit your next manuscript to BioMed Central and take full advantage of:}

- Convenient online submission

- Thorough peer review

- No space constraints or color figure charges

- Immediate publication on acceptance

- Inclusion in PubMed, CAS, Scopus and Google Scholar

- Research which is freely available for redistribution

Submit your manuscript at www.biomedcentral.com/submit
Biomed Central 